\title{
(6) OPEN ACCESS \\ Use of the pCONus as an adjunct to coil embolization of acutely ruptured aneurysms
}

\author{
M Aguilar Pérez, ${ }^{1} \mathrm{P}$ Bhogal, ${ }^{1} \mathrm{R}$ Martinez Moreno, ${ }^{1} \mathrm{C}$ Wendl, ${ }^{1} \mathrm{H}$ Bäzner, ${ }^{2}$ \\ 0 Ganslandt, ${ }^{3} \mathrm{H}^{1}$ Henkes $^{1,4}$
}

${ }^{1}$ Neuroradiological Clinic, Neurocenter, Klinikum Stuttgart, Stuttgart, Germany ${ }^{2}$ Neurological Clinic, Neurocenter, Klinikum Stuttgart, Stuttgart, Germany ${ }^{3}$ Neurosurgical Clinic, Neurocenter, Klinikum Stuttgart, Stuttgart, Germany ${ }^{4}$ Medical Faculty, University Duisburg-Essen, Germany

\section{Correspondence to} Dr M Aguilar Perez, Neuroradiological Clinic, Neurocenter, Klinikum Stuttgart, Kriegsbergstrasse 60, Stuttgart 70174, Germany; M.Aguilar@klinikum-stuttgart.de

Received 9 May 2016 Revised 9 June 2016 Accepted 17 June 2016 Published Online First 13 July 2016

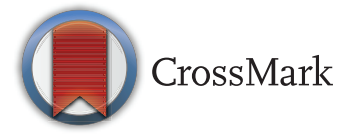

To cite: Pérez $M A$, Bhogal P, Moreno RM, et al. I Neurolntervent Surg 2017:9:39-44.

\begin{abstract}
Introduction Coil embolization of ruptured aneurysms has become the standard treatment in many situations. However, certain aneurysm morphologies pose technical difficulties and may require the use of adjunctive devices. Objective To present our experience with the pCONus, a new neck bridging device, as an adjunct to coil embolization for acutely ruptured aneurysms and discuss the technical success, angiographic and clinical outcomes. Methods We conducted a retrospective review of our database of prospectively collected data to identify all patients who presented with acute subarachnoid hemorrhage that required adjunctive treatment with the pCONus in the acute stage. We searched the database between April 2011 and April 2016.
\end{abstract}

Results 21 patients were identified ( 13 male, 8 female) with an average age of 54.6 years (range 31-73). 8 aneurysms were located at the basilar artery tip, 7 at the anterior communicating artery, 4 at the middle cerebral artery bifurcation, 1 pericallosal, and 1 basilar fenestration. $61.8 \%$ patients achieved modified Raymond-Roy classification I or II at immediate angiography, with $75 \%$ of patients having completely occluded aneurysms or stable appearance at initial followup. There were no repeat aneurysmal ruptures and two device-related complications (no permanent morbidity). Four patients in our cohort died.

Conclusions Use of the pCONus is safe and effective in patients with acutely ruptured aneurysms and carries a high rate of technical success.

\section{INTRODUCTION}

In recent times a growing number of devices have been produced to attempt to deal with the challenging anatomy of some bifurcation aneurysms, including the pCONus (Phenox). These devices represent an advancement of the previously described waffle cone technique, ${ }^{1}$ where a selfexpanding stent is placed into the afferent artery and its distal end is implanted in the neck of the aneurysm so as to provide a barrier for stabilizing the coil ball mass within the aneurysm. Both of the aforementioned devices go one step beyond this concept and provide more definitive protection at the aneurysmal neck and hence allow protection of any vessels that may arise from this region.

The pCONus device has a CE mark and is available for use in Europe but does not have Food and Drug Administration clearance for use in the USA. It is an electrolytically detachable laser cut stent with a distal crown and four petals that are deployed in the aneurysm with its base at the level of the aneurysm neck. At the distal end of the stent six polyamide fibers form a cross that provides further support to the coil ball mass (figure 1). A proximal marker and four radio-opaque markers, one on each of the petals, allow accurate positioning of the device. The distal parts of the petals remain invisible on fluoroscopy and it is important to realize this as these may be in contact with the aneurysm wall. The device is available in six distal petal diameters $5,6,8,10,12$, and $15 \mathrm{~mm}$. The diameter of the shaft is $4 \mathrm{~mm}$ and the shaft is available in 20 or $25 \mathrm{~mm}$ lengths.

Several publications have examined the use of the pCONus. ${ }^{2-5}$ However, no publications have yet focused on use of the device for acutely ruptured aneurysms. In this study we present our experience with the pCONus used exclusively in acutely ruptured aneurysms.

\section{MATERIALS AND METHODS}

We retrospectively reviewed our database of prospectively collected data to identify all patients who presented to our department with acute subarachnoid hemorrhage and underwent pCONus-assisted coil embolization of the ruptured aneurysm. We searched the database between April 2011 and April 2016 and identified 21 patients.

Subarachnoid hemorrhage was confirmed on CT imaging. Hunt and Hess score as well as Fisher grading was recorded for all patients at presentation. The decision to place an extraventricular drain was taken in agreement with the neurosurgical department.

All patients gave informed consent and the use of the pCONus device was used at the discretion of the operator. All patients were treated under general anesthesia. Before treatment the patients received dual antiplatelet therapy with aspirin and clopidogrel. Platelet function was tested in all patients using the Multiplate device (Verum Diagnostica, Munich, Germany) and if platelet inhibition was poor with clopidogrel, treatment was changed to ticagrelor.

A standard 6Fr right common femoral approach was used for all cases. Patients were fully heparinized with a $5000 \mathrm{IU}$ bolus dose of heparin and given repeated bolus doses of heparin to maintain the activated clotting time at 2-2.5 times normal. Rotational angiography was used to accurately ascertain the anatomy of the aneurysm, afferent artery, and any vessels derived from the neck of the aneurysm. This was also used to correctly size the pCONus device to both the afferent artery and the 
Figure 1 Photos of a pCONus device showing the stent-like shaft, the four distal petals that rest within the aneurysm, and the polyamide fibers that cross the distal end of the stent and provide a further mechanical barrier.

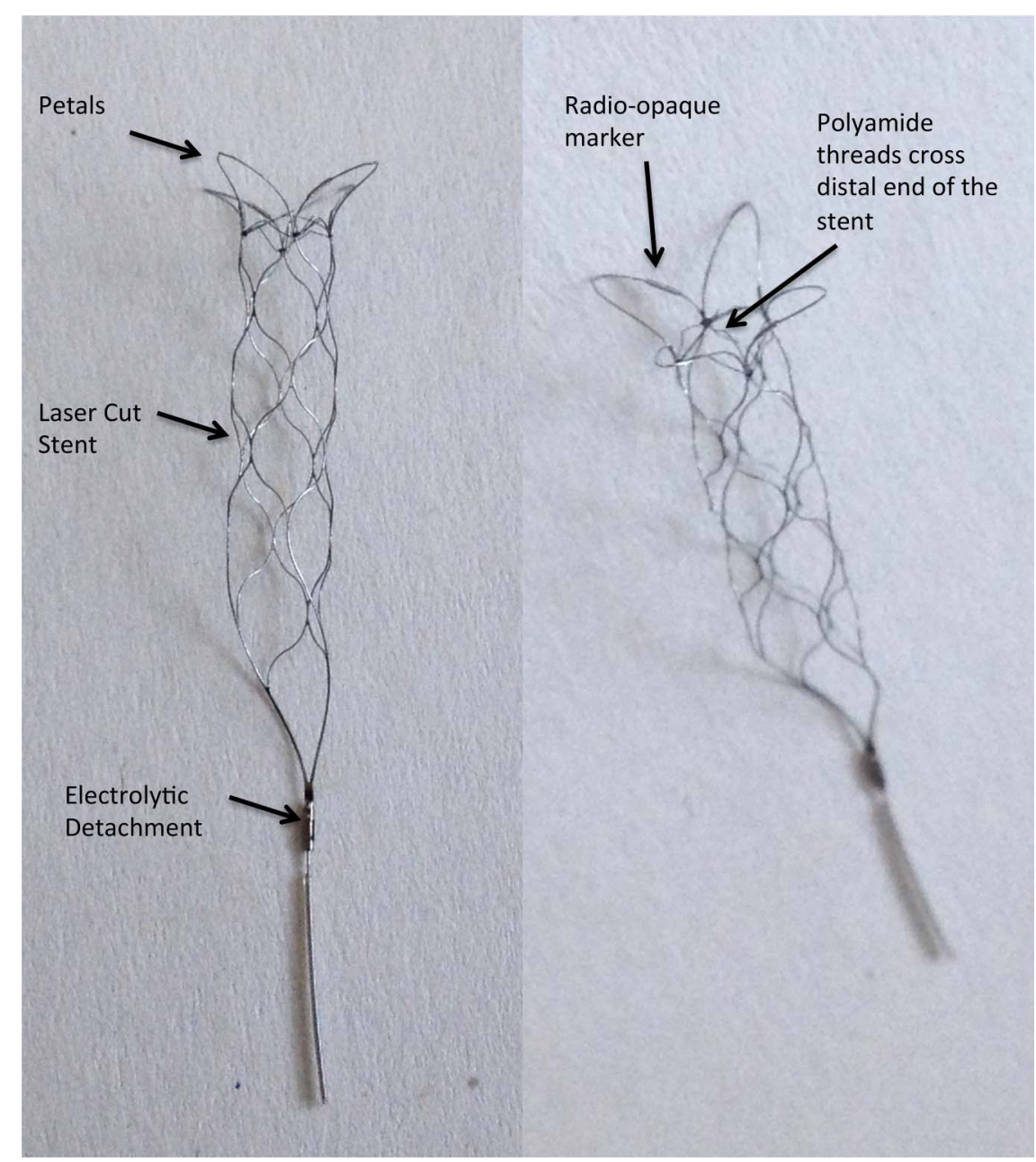

aneurysm neck/base. In all cases the pCONus was delivered first and then the device crossed with the coiling catheter. The pCONus was not detached until satisfactory coiling of the aneurysm had been achieved

\section{Clinical events}

Any clinical events that occurred in the postoperative period were recorded. A neurological assessment was performed before the treatment, after the treatment, at discharge, and at follow-up.

\section{Radiological follow-up}

Standard Towne's and lateral angiographic images were acquired for all patients before treatment, in addition to rotational angiographic images, in order to determine the most suitable projection to allow visualization of the afferent artery, the aneurysm, and any branches that needed preserving. Control angiography was performed at the end of the procedure. The angiographic projection used to perform the coiling procedure was replicated in follow-up angiography.

Immediate aneurysm occlusion at the end of the procedure was based upon the modified Raymond-Roy classification (mRRC). Aneurysm changes were documented on serial angiography (ie, increase or decrease in the size of the aneurysm remnant or in any neck remnants) and were again graded using the mRRC scale. The mRRC scale is a four-point scale that records the occlusion of aneurysms as complete (mRRC I), neck remnant (mRRC II), contrast filling seen between the coil loop interstices (mRRC IIIa), and contrast filling seen between the coil loop interstices and the aneurysm wall (mRRC IIIb). ${ }^{6}$

The initial angiographic follow-up was performed between 3 and 6 months after coiling, with a further follow-up performed at 12 months.

\section{RESULTS}

Twenty-one patients (13 men, 8 women) who presented with acute hemorrhage secondary to aneurysmal rupture were treated in the acute phase with adjunctive use of the pCONus device. The average age of the patients was 54.6 years (range 31-73). Aneurysms ranged in size and location with the average aneurysm dome width being $9.4 \mathrm{~mm}$ (range 3.2-14.6) and the average neck width $6.4 \mathrm{~mm}$ (range 3-11.1). All the patients presented with hemorrhage, with one patient presenting with pure intracerebral hemorrhage and one patient with both intracerebral hemorrhage and subarachnoid hemorrhage. The remainder of the cases presented with subarachnoid hemorrhage. A single pCONus was used in all cases. Eleven of the patients required an endoventricular drain and in all cases this was inserted before occlusion of the aneurysm and deployment of the pCONus. There were no major hemorrhages associated with the ventricular drains.

The basilar tip was the most common location $(n=8)$, followed by the anterior communicating artery $(n=7)$, four middle cerebral artery (MCA) bifurcation aneurysms (three on the right and one on the left) with single cases involving a pericallosal location, and a basilar fenestration aneurysm. The results are summarized in table 1. 


\begin{tabular}{|c|c|c|c|c|c|c|c|c|c|c|c|c|c|c|}
\hline Patient & $\begin{array}{l}\text { Hunt } \\
+ \text { +Hess }\end{array}$ & $\begin{array}{l}\text { Fisher } \\
\text { score }\end{array}$ & $\begin{array}{l}\text { Aneurysm } \\
\text { location }\end{array}$ & $\begin{array}{l}\text { Neck } \\
\text { width }\end{array}$ & $\begin{array}{l}\text { Dome } \\
\text { width }\end{array}$ & $\begin{array}{l}\text { Dome/neck } \\
\text { ratio }\end{array}$ & $\begin{array}{l}\text { Endoventricular } \\
\text { drain }\end{array}$ & $\begin{array}{l}\text { Before } \\
\text { medication }\end{array}$ & $\begin{array}{l}\text { After } \\
\text { medication }\end{array}$ & $\begin{array}{l}\text { Intraoperative } \\
\text { complications }\end{array}$ & $\begin{array}{l}\text { Immediate } \\
\text { postoperative } \\
\text { mRRC }\end{array}$ & $\begin{array}{l}\text { First } \\
\text { follow-up } \\
\text { (months) }\end{array}$ & $\begin{array}{l}\text { Radiographic outcome at } \\
\text { delayed follow-up (mRRC) }\end{array}$ & $\begin{array}{l}\text { Final } \\
\text { mRS }\end{array}$ \\
\hline 1 & IV & IV & Basilar tip & 7.2 & 13.5 & 1.87 & Y-pre-op & $\begin{array}{l}500 \text { ASA IV, } 600 \\
\text { clopidogrel p.o. }\end{array}$ & Clopidogrel & No & Illb & 2 & Stable neck remnant (IIlb) & 1 \\
\hline 2 & V & IV & AcomA & 6.1 & 8.5 & 1.4 & $\mathrm{Y}$-pre-op & $2 \times 500 \mathrm{mg}$ ASA IV & Clopidogrel & No & IIIlb & Dead & Dead & 6 \\
\hline 3 & IV & IV & Basilar tip & 11.1 & 14.4 & 1.3 & $\mathrm{Y}$-pre-op & $\begin{array}{l}500 \text { ASA IV, } 300 \\
\text { clopidogrel p.o. }\end{array}$ & Clopidogrel & No & IIIlb & Dead & Dead & 6 \\
\hline 4 & IV & IV & Basilar tip & 4.4 & 5.1 & 1.16 & Y-pre-op & $\begin{array}{l}2 \times 500 \text { ASA IV, } 600 \\
\text { clopidogrel p.o. }\end{array}$ & Clopidogrel & No & । & Dead & Dead & 6 \\
\hline 5 & ॥ & IV & Right MCA & 10.6 & 13.2 & 1.24 & $\mathrm{Y}$-pre-op & $\begin{array}{l}500 \text { ASA IV, } 300 \\
\text { clopidogrel p.o. }\end{array}$ & Clopidogrel & No & IIIb & 2 & $\begin{array}{l}\text { Compaction and growth (IIIlb) } \\
\text {-re-treatment }\end{array}$ & 0 \\
\hline 6 & IV & IV & AcomA & 3 & 3.2 & 1.06 & $Y$-pre-op & $\begin{array}{l}500 \text { ASA IV, } 600 \\
\text { clopidogrel p.o. }\end{array}$ & Clopidogrel & Thrombus in A1 & I & 3 & Complete occlusion (I) & 0 \\
\hline 7 & ॥ & III & AcomA & 4.4 & 6 & 1.36 & $\mathrm{~N}$ & $\begin{array}{l}\text { ASA IV, clopidogrel p.o. } \\
\text { and eptifibatide IV }\end{array}$ & Clopidogrel & No & I & 6 & Complete occlusion (I) & 1 \\
\hline 8 & ॥ & IV & $\begin{array}{l}\text { BA } \\
\text { fenestration }\end{array}$ & 9.6 & 13.4 & 1.4 & $\mathrm{Y}$-pre-op & $\begin{array}{l}\text { ASA IV, clopidogrel p.o. } \\
\text { and eptifibatide IV }\end{array}$ & Clopidogrel & No & ॥ & Dead & Dead & 6 \\
\hline 9 & III & IV & Basilar tip & 7.8 & 11.1 & 1.42 & $Y$-pre-op & $\begin{array}{l}\text { ASA IV, ticagrelor p.o. } \\
\text { and eptifibatide IV }\end{array}$ & Brilique & No & I & 4 & Complete occlusion (I) & 1 \\
\hline 10 & I & III & Right MCA & 8.5 & 11.9 & 1.4 & $\mathrm{~N}$ & $\begin{array}{l}\text { ASA IV, ticagrelor p.o. } \\
\text { and eptifibatide IV }\end{array}$ & Brilique & No & Illlb & 3 & Stable neck remnant (IIlb) & 0 \\
\hline 11 & 1 & ॥ & AcomA & 6.25 & 8.03 & 1.28 & $\mathrm{~N}$ & $\begin{array}{l}\text { Loading ASA IV and } \\
\text { ticagrelor p.o. }\end{array}$ & Brilique & No & I & 3 & Small neck recurrence (II) & 0 \\
\hline 12 & I & ॥ & Basilar tip & 5.52 & 8.2 & 1.48 & $\mathrm{~N}$ & $\begin{array}{l}\text { ASA IV, ticagrelor p.o. } \\
\text { and eptifibatide IV }\end{array}$ & Brilique & No & 1 & 3 & Complete occlusion (I) & 0 \\
\hline 13 & ॥ & IV & Basilar tip & 5.3 & 10.7 & 2 & $Y$-pre-op & $\begin{array}{l}\text { ASA IV, ticagrelor p.o. } \\
\text { and eptifibatide IV }\end{array}$ & Brilique & No & I & 5 & $\begin{array}{l}\text { Coil compaction }+ \text { small neck } \\
\text { recurrence (II)—re-treatment }\end{array}$ & 0 \\
\hline 14 & $\mathrm{v}$ & IV & Basilar tip & 5.5 & 6.3 & 1.14 & $\mathrm{Y}$-pre-op & $\begin{array}{l}\text { ASA IV, ticagrelor p.o. } \\
\text { and eptifibatide IV }\end{array}$ & Clopidogrel & No & I & 7 & Complete occlusion (I) & 0 \\
\hline 15 & III & IV & AcomA & 5.5 & 14.6 & 2.65 & $Y$-pre-op & $\begin{array}{l}\text { ASA IV, ticagrelor p.o. } \\
\text { and eptifibatide IV }\end{array}$ & Brilique & No & Illa & 9 & Complete occlusion (I) & 2 \\
\hline 16 & I & I & Basilar tip & 7.76 & 9.2 & 1.18 & $\mathrm{~N}$ & $\begin{array}{l}\text { Loading ASA IV and } \\
\text { ticagrelor p.o. }\end{array}$ & Brilique & No & IIIb & 2 & Complete occlusion (I) & 2 \\
\hline 17 & III & III & Left MCA & 5 & 4 & 0.8 & $\mathrm{~N}$ & $\begin{array}{l}\text { ASA IV, ticagrelor p.o. } \\
\text { and eptifibatide IV }\end{array}$ & Brilique & No & ॥ & 2 & $\begin{array}{l}\text { Stable neck remnant (II)-re- } \\
\text { treatment }\end{array}$ & 1 \\
\hline 18 & I & 1 & Right MCA & 3 & 3.4 & 1.13 & $\mathrm{~N}$ & $\begin{array}{l}\text { ASA IV, ticagrelor p.o. } \\
\text { and eptifibatide IV }\end{array}$ & Brilique & No & ॥ & 3 & Complete occlusion (I) & 1 \\
\hline 19 & I & I & AcomA & 8.5 & 14.1 & 1.66 & $\mathrm{~N}$ & $\begin{array}{l}\text { ASA IV, ticagrelor p.o. } \\
\text { and eptifibatide IV }\end{array}$ & Brilique & $\begin{array}{l}\text { Perforation } \\
+ \text { thrombus }\end{array}$ & ॥ & 3 & Neck recurrence & 0 \\
\hline 20 & I & I & AcomA & 4 & 7 & 1.75 & $\mathrm{~N}$ & $\begin{array}{l}\text { ASA IV, ticagrelor p.o. } \\
\text { and eptifibatide IV }\end{array}$ & Brilique & No & I & 3 & Complete occlusion (I) & 0 \\
\hline 21 & I & III & Pericallosal & 6 & 12 & 2 & $\mathrm{~N}$ & $\begin{array}{l}\text { ASA IV, ticagrelor p.o. } \\
\text { and eptifibatide IV }\end{array}$ & $\begin{array}{l}\text { Aspirin and } \\
\text { Brilique }\end{array}$ & & IIllb & None yet & None yet & N/A \\
\hline
\end{tabular}




\section{Immediate angiographic results}

In all cases the pCONus was deployed successfully before coiling according to the standard technique for use of the device. The angiographic results achieved at the end were recorded using the mRRC. ${ }^{6}$ Nine patients $(42.9 \%)$ had complete occlusion of the aneurysm (mRRC I), four patients (19\%) had a neck remnant (mRRC II); in one of these this was planned to preserve a vessel derived from the neck of the aneurysm that was believed to represent the subcallosal artery and would have been difficult to preserve even with surgery. One patient (4.8\%) had filling between the interstices of the coils (mRRC IIIa) and the remaining seven patients $(33.3 \%)$ had filling between the coil ball mass and the wall of the aneurysm (mRRC IIIb).

\section{Clinical and angiographic follow-up}

In our cohort four patients died all of whom had Fisher grade IV hemorrhage on their initial CT scans. Of the remaining patients, all had a final modified Rankin Scale (mRS) score $<2$ with seven patients $\mathrm{mRS} 0$, four patients $\mathrm{mRS} 1$, and two patients mRS 2 at last follow-up.

Initial angiographic follow-up was performed in 16 patients (four had died and one patient had not yet had follow-up angiography) at an average of 5.5 months after the procedure (range 2-9 months). Of these patients, nine had completely occluded aneurysms (six that were initially mRRC I, one was initially class II, one patient initially class mRRC IIIa, and one initially mRRC IIIb). Three patients had stable remnants (figure 2) and recurrence was seen in the remaining four patients, one of whom had a planned neck remnant due to the small vessel arising from the neck (figures 3 and 4).

\section{Complications}

Intraoperative complications were seen in two patients. In one patient (no 6) non-occlusive thrombus was seen to be forming around the struts of the pCONus device during the coiling procedure. However, after IA bolus does of eptifibatide and IV aspirin this resolved. There were no clinical or radiological consequences.

In another patient (figure 5, patient 19), after deployment of the pCONus, which itself was uneventful, angiography revealed a slow contrast leak from the aneurysm. This was believed to be secondary to a rupture of the aneurysm caused by the pCONus. Because of the likely aneurysmal rupture the bolus dose of eptifibatide was not given and the aneurysm was quickly occluded. Angiography at the end of the procedure showed complete occlusion of the A1. This completely resolved after a bolus dose of IA eptifibatide. There were no clinical or radiological consequences.

There were no aneurysmal re-ruptures following treatment. Four patients died in our cohort (19\%).

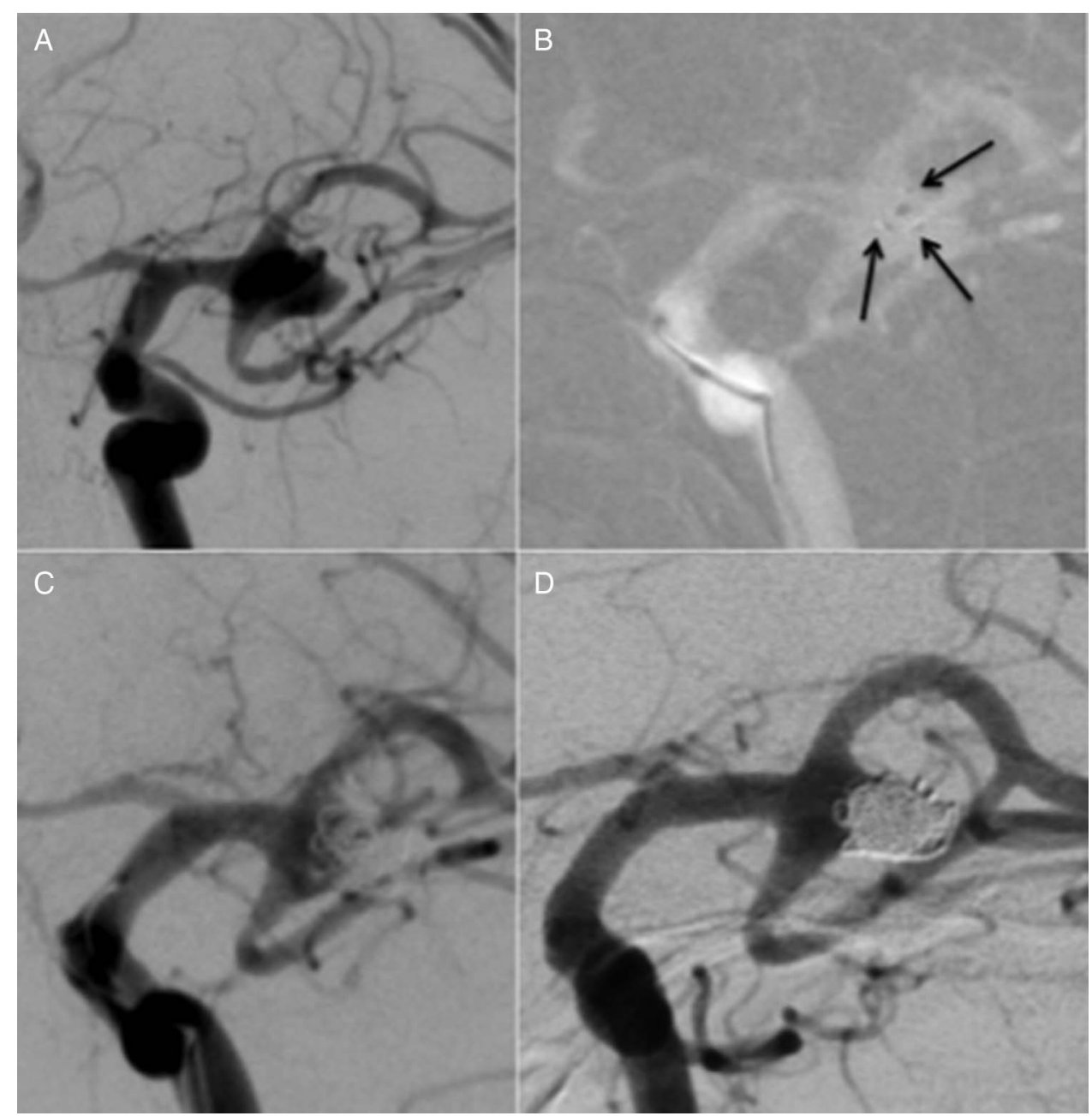

Figure 2 A wide-necked left middle cerebral artery bifurcation aneurysm (A). This was treated with a pCONus ((B) black arrows point to the intra-aneurysmal pCONus markers) and coiling with a neck remnant seen at the end of the procedure (C). At follow-up performed at 2 months, the neck remnant is stable (D). 
Figure 3 A large Acom aneurysm with the likely rupture bleb $(A)$. $A$ small branch could be seen arising from the neck of the aneurysm and this was thought to possibly represent the subcallosal artery ( $B$, white arrows) and therefore was important to preserve.
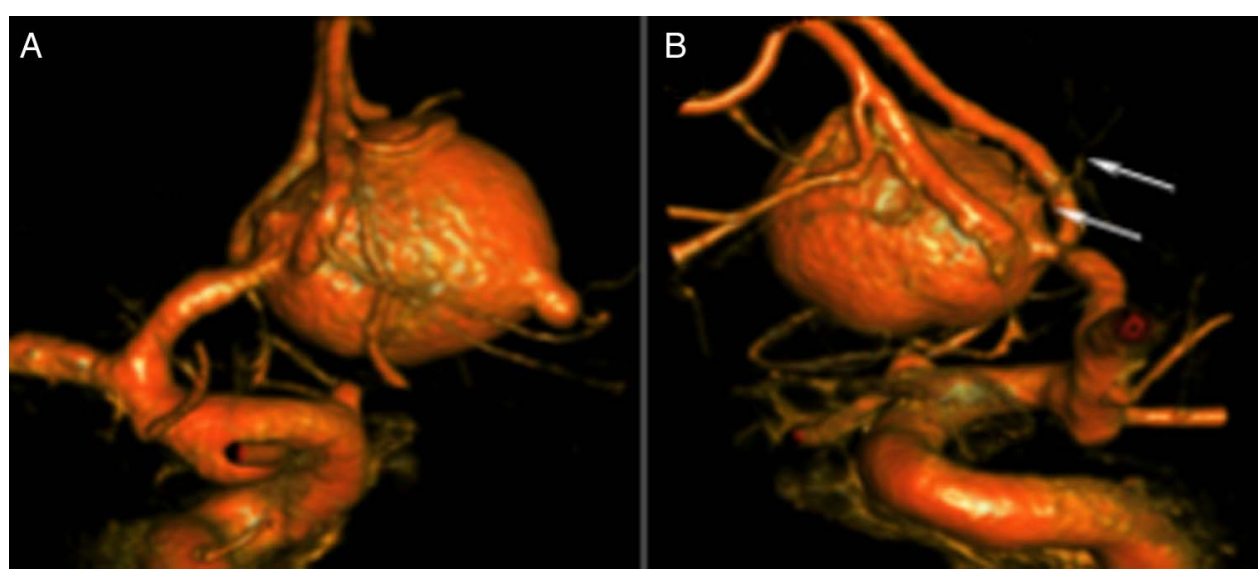

\section{DISCUSSION}

Since the publication of the pivotal ISAT study, ${ }^{7}$ endovascular treatment of aneurysms has become the first-line treatment for many aneurysms. Surgical clipping remains an option for many complex aneurysms with unfavorable anatomy for endovascular coiling. These aneurysms have classically involved those with wide necks and/or arterial branches from the neck that may not be easily protected during endovascular procedures. If endovascular treatment is pursued then adjunctive use of balloons or stents may be required. Gory et $a l^{2}$ recently published their series of 131 non-selected aneurysms of the MCA bifurcation and in this cohort $60.3 \%$ of aneurysms required balloon remodeling. The use of balloon remodeling in either ruptured or unruptured aneurysms does not appear to be associated with an increase in morbidity or mortality. ${ }^{8}$ However, the use of balloons does add to the complexity of the procedure and the duration of the treatment as well as fluoroscopic time. Stent-assisted coiling can also be used for aneurysms with complicated anatomy and for the preservation of arteries derived from the aneurysmal neck. Some evidence suggests that the use of stents in such cases carries low levels of morbidity and mortality. ${ }^{9-12}$ However, other studies have suggested that the use of intracranial stents increases the risk of clinically evident complications. $^{13} 14$

The use of stents in patients with subarachnoid hemorrhage is considered by many to expose patients to increased risk as the use of stents necessitates antiplatelet medication and if interventions such as extraventricular drain placement are later required. ${ }^{15-19}$ Bodily et $a l^{20}$ reviewed the use of stents in patients with acute subarachnoid hemorrhage and found hemorrhagic complications in 27/339 patients, a third of which were ventricular drain-related hemorrhages. Clinically significant thromboembolic events occurred in $6 \%$ of patients, with no patients having both thromboembolic and hemorrhagic events. The authors concluded that the use of stents in patients with subarachnoid hemorrhage carries a higher rate of adverse clinical events than in those patients in whom stents are not used. Several limitations to this publication are acknowledged, including a high likelihood of publication bias and disparate populations. Only one case in our cohort had a hemorrhagic complication (4.7\%), which occurred during deployment of the pCONus device within the aneurysm. Additionally, in our cohort all the patients who required a ventricular drain had one inserted before treatment of the aneurysm and start of antiplatelet medication. No ventricular drains were associated with hemorrhages in our cohort.

Previous authors have published their experience with the pCONus device. Lubicz et $a l^{3}$ reported their series of 18 patients with 19 unruptured aneurysms. In that series two patients had clinical complications, neither of which was hemorrhagic. Complete aneurysm occlusion was seen in 12 aneurysms. Fischer et $a l^{5}$ reported on their series of 25 patients, seven of whom had acutely ruptured aneurysms. Of these seven patients, two died as a consequence of subarachnoid hemorrhage. Of the remaining five patients, four had good functional recovery $(m R S<3)$ and one patient had a final mRS of 3 . In total four patients had complications, excluding death, only one of which resulted in a permanent deficit. Similar results were reported by Gory et $a l^{21}$ in their study of wide-necked MCA aneurysms treated with the device. Four patients were treated in the acute phase and two patients had complications, neither of which was permanent and again no cases of intraoperative rupture occurred. To date the series that included the most ruptured aneurysms was that of Aguilar-Pérez et al, ${ }^{4}$ with nine ruptured

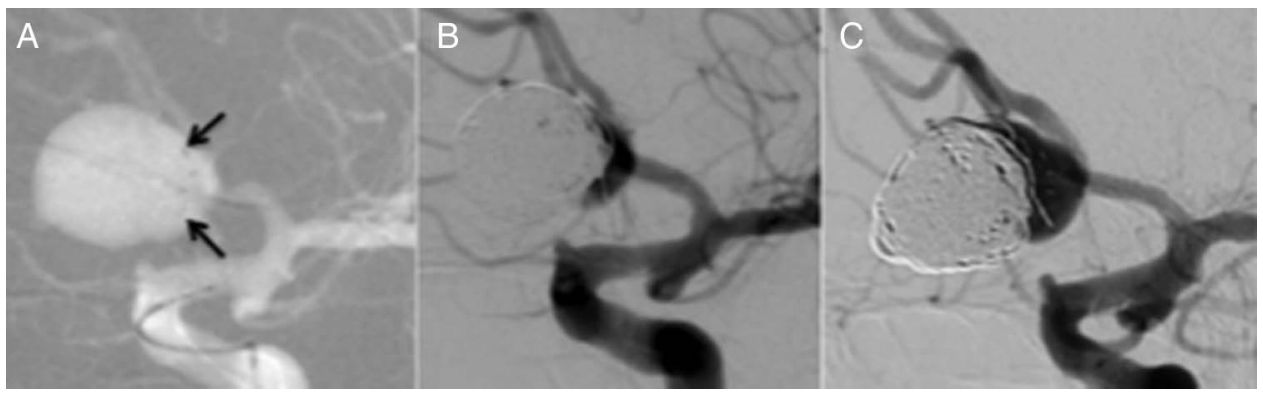

Figure 4 The same patient as in figure 3. Two of the markers for the pCONus device can be seen (A, black arrows) within the aneurysm sac. Subsequent to the deployment of the pCONus the aneurysm was coiled leaving a neck remnant (B). Follow-up angiography performed at 3 months shows enlargement of the neck remnant. 
Figure 5 A ruptured multi-lobulated anterior communicating aneurysm (A). After deployment of the pCONus device in the aneurysm, angiography showed a slow contrast leak (B and C) that was thought to represent rupture of the aneurysm during deployment of the device. Because of the aneurysmal rupture the bolus dose of eptifibatide, as is our standard practice, was not given upon deployment of the pCONus. The aneurysm was quickly coiled with complete occlusion of the aneurysm. However, angiography showed that thrombosis had developed within the pCONus device and the A1 segment (D). This was treated with a bolus dose of eptifibatide, with complete recanalization of the vessel and no clinical or radiological evidence of infarction ( $E$ ). A follow-up angiogram performed at 3 months shows stable complete occlusion of the aneurysm (F).
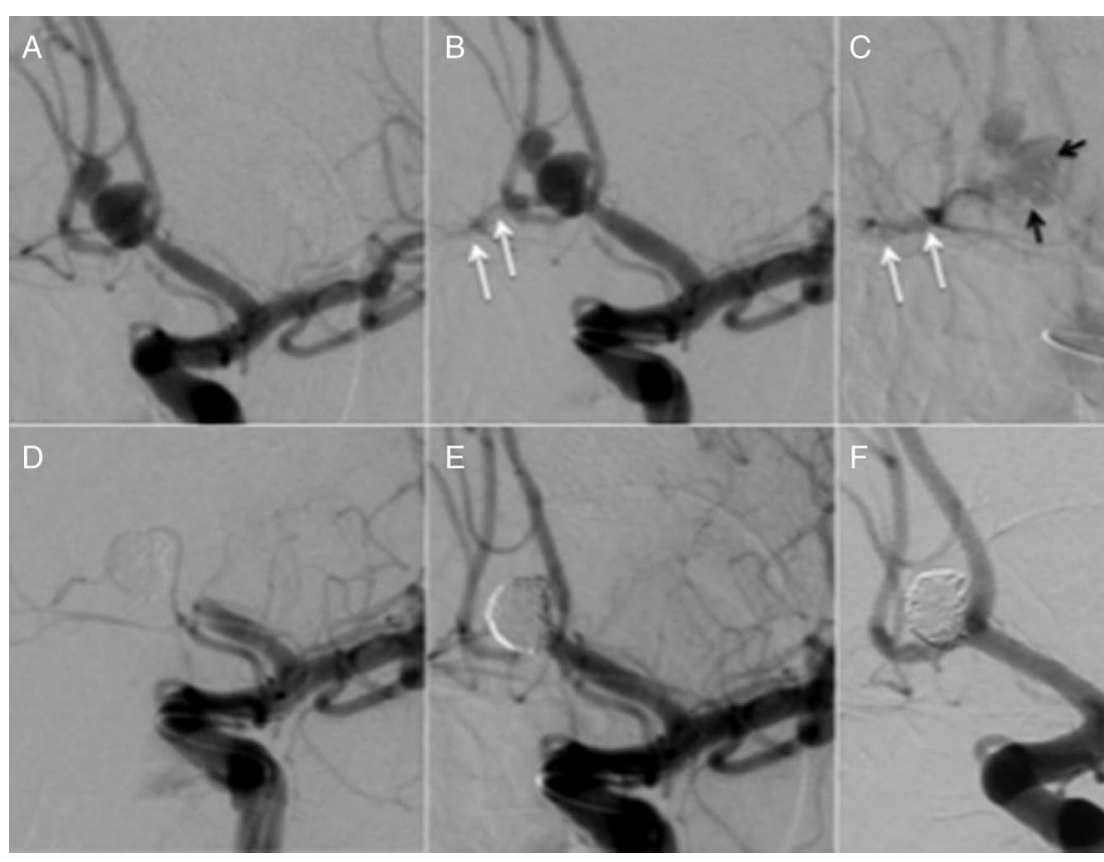

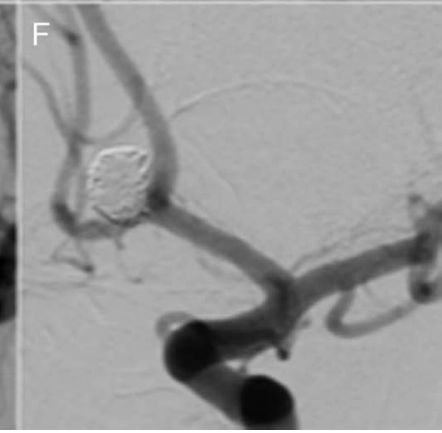

aneurysms. There were no cases of intra-operative aneurysmal rupture or of hemorrhagic complications in this series. They also reported no clinically evident complications associated with the use of the pCONus device.

The placement of a stent that is directed towards the aneurysm may be considered by some to direct the flow into the aneurysm. However, this was recently shown not to be the case. Pérez et $a l^{22}$ recently demonstrated that neither a Solitaire stent placed in a waffle cone technique, nor a pCONus device resulted in increased flow into the aneurysm. Indeed, the study showed rather a mild decrease in intra-aneurysmal flow with both devices, and no significant flow-diverting effect due to the device, as has been suggested with Y stenting. ${ }^{23}$ Therefore, we believe that it is important for the initial treatment to achieve a high rate of aneurysm exclusion in order to adequately protect the aneurysm from re-rupture, which we did not see in our cohort, and also to avoid re-treatment at a later stage. In our study $62 \%(13 / 21)$ patients achieved mRRC grade I or II aneurysm exclusion and at follow-up 13 of the surviving 16 patients $(81 \%)$ with available follow-up imaging had either completely excluded aneurysms or stable remnants. Additionally, we believe that the low metal coverage of the pCONus does not preclude subsequent treatments and that the stability afforded by the device at the neck of the aneurysm and on the coil ball mass will help to prevent any coil loops being dislodged during any subsequent treatments.

Our study has several limitations, including the single-center retrospective design and the relatively small number of patients. Longer-term follow-up is required to assess for delayed aneurysm recurrence and hemorrhagic complications.

\section{CONCLUSION}

The use of the pCONus device in patients with acutely ruptured intracranial aneurysms appears to be safe and carries a high rate of technical success as well as good rates of aneurysmal exclusion. Long-term follow-up is required to fully assess the efficacy of this device in patients with acutely ruptured intracranial aneurysms.

Twitter Follow Marta Perez at @MartaAguilarPe2
Contributors MAP, PB, RMM, CW: data gathering, manuscript preparation. OG, $H B$ : review, editing. $H H$ : guarantor, overall review, study design.

Competing interests $M A P, P B$, and RMM serve as proctors and consultants for phenox $\mathrm{GmbH}$, and receive moderate financial compensation. $\mathrm{HH}$ is a co-founder and shareholder of phenox $\mathrm{GmbH}$.

Provenance and peer review Not commissioned; externally peer reviewed.

Open Access This is an Open Access article distributed in accordance with the Creative Commons Attribution Non Commercial (CC BY-NC 4.0) license, which permits others to distribute, remix, adapt, build upon this work non-commercially, and license their derivative works on different terms, provided the original work is properly cited and the use is non-commercial. See: http://creativecommons.org/ licenses/by-nc/4.0/

\section{REFERENCES}

Horowitz M, Levy E, Sauvageau E, et al. Intra/extra-aneurysmal stent placement for management of complex and wide-necked- bifurcation aneurysms: eight cases using the waffle cone technique. Neurosurgery 2006;58:ONS-258-62; discussion ONS-262.

2 Gory B, Rouchaud A, Saleme S, et al. Endovascular treatment of middle cerebral artery aneurysms for 120 nonselected patients: a prospective cohort study. AJNR Am J Neuroradiol 2014;35:715-20.

3 Lubicz B, Morais R, Alghamdi F, et al. The pCONus device for the endovascular treatment of wide neck bifurcation aneurysms. J Neurointerv Surg 2016;8: 940-4.

4 Aguilar-Pérez M, Kurre W, Fischer S, et al. Coil occlusion of wide-neck bifurcation aneurysms assisted by a novel intra- to extra-aneurysmatic neck-bridging device (pCONus): initial experience. AJNR Am J Neuroradiol 2014;35:965-71.

5 Fischer $S$, Weber $A$, Titschert A, et al. Single-center experience in the endovascular treatment of wide-necked intracranial aneurysms with a bridging intra-/ extra-aneurysm implant (pCONus). J Neurointerv Surg 2016;8:1186-91.

6 Mascitelli JR, Moyle H, Oermann EK, et al. An update to the Raymond-Roy occlusion classification of intracranial aneurysms treated with coil embolization. J Neurointerv Surg 2015;7:496-502.

7 Molyneux A, Kerr R, Stratton I, et al. International Subarachnoid Aneurysm Trial (ISAT) of neurosurgical clipping versus endovascular coiling in 2143 patients with ruptured intracranial aneurysms: a randomised trial. Lancet 2002;360:1267-74.

8 Pierot L, Spelle L, Leclerc $X$, et al. Endovascular treatment of unruptured intracranial aneurysms: comparison of safety of remodeling technique and standard treatment with coils. Radiology 2009;251:846-55.

9 Biondi A, Janardhan V, Katz JM, et al. Neuroform stent-assisted coil embolization of wide-neck intracranial aneurysms: strategies in stent deployment and midterm follow-up. Neurosurgery 2007;61:460-8; discussion 468-9.

10 Gentric JC, Biondi A, Piotin M, et al. Safety and efficacy of neuroform for treatment of intracranial aneurysms: a prospective, consecutive, French multicentric study. AJNR Am J Neuroradiol 2013;34:1203-8. 


\section{Hemorrhagic stroke}

11 Gory B, Klisch J, Bonafé A, et al. Solitaire AB stent-assisted coiling of wide-necked intracranial aneurysms: mid-term results from the SOLARE Study. Neurosurgery 2014;75:215-9; discussion 219.

12 Jeong HW, Seung W-B. Outcomes of stent-assisted coil embolization of wide-necked intracranial aneurysms using the Solitaire ${ }^{T M} A B$ neurovascular remodeling device. J Cerebrovasc Endovasc Neurosurg 2015;17:301-12.

13 Bartolini B, Blanc $R$, Pistocchi $S$, et al. ' $Y$ ' and ' $X$ ' stent-assisted coiling of complex and wide-neck intracranial bifurcation aneurysms. AJNR Am J Neuroradiol 2014;35:2153-8.

14 Piotin M, Blanc R, Spelle L, et al. Stent-assisted coiling of intracranial aneurysms: clinical and angiographic results in 216 consecutive aneurysms. Stroke J Cereb Circ 2010;41:110-15.

15 Sani S, Jobe KW, Lopes DK. Treatment of wide-necked cerebral aneurysms with the Neuroform2 Treo stent. A prospective 6-month study. Neurosurg Focus 2005;18:E4

16 Alfke K, Straube T, Dörner L, et al. Treatment of intracranial broad-neck aneurysms with a new self-expanding stent and coil embolization. AJNR Am J Neuroradiol 2004;25:584-91.

17 dos Santos Souza MP, Agid R, Willinsky RA, et al. Microstent-assisted coiling for wide-necked intracranial aneurysms. Can J Neurol Sci J Can Sci Neurol 2005;32:71-81.
18 Mocco J, Snyder KV, Albuquerque FC, et al. Treatment of intracranial aneurysms with the Enterprise stent: a multicenter registry. J Neurosurg 2009;110:35-9.

19 Katsaridis V, Papagiannaki C, Violaris C. Embolization of acutely ruptured and unruptured wide-necked cerebral aneurysms using the neuroform 2 stent without pretreatment with antiplatelets: a single center experience. AJNR Am J Neuroradiol 2006;27:1123-8

20 Bodily KD, Cloft HJ, Lanzino G, et al. Stent-assisted coiling in acutely ruptured intracranial aneurysms: a qualitative, systematic review of the literature. AJNR Am J Neuroradiol 2011;32:1232-6.

21 Gory B, Aguilar-Pérez M, Pomero E, et al. pCONus device for the endovascular treatment of wide-neck middle cerebral artery aneurysms. AJNR Am J Neuroradiol 2015;36:1735-40.

22 Pérez $M A$, Henkes $H$, Bouillot $P$, et al. Intra-aneurysmal hemodynamics: evaluation of pCONus and pCANvas bifurcation aneurysm devices using DSA optical flow imaging. J Neurointerv Surg 2016;8:1197-201.

23 Cantón G, Levy DI, Lasheras JC, et al. Flow changes caused by the sequential placement of stents across the neck of sidewall cerebral aneurysms. J Neurosurg 2005:103:891-902 